\title{
NECROLÓGIO
}

\section{PAUL CHESTER BEAVER (1905-1993)}

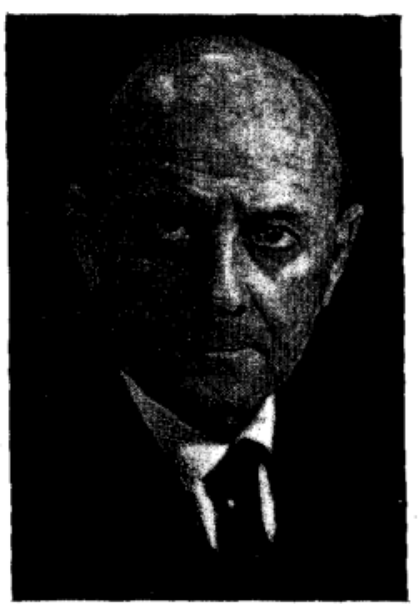

Dr. Beaver died on December 23, 1993 at age 88. He was the last student of Dr. Henry Baldwing Ward, the father of medical parasitology in the US. $\mathrm{Dr}$. Beaver received both an $\mathrm{MS}$ and $\mathrm{ahD}$ from the University of Illinois (1929 and 1935). His postdoctoral studies were in comparative pathology at the University of Chicago. In 1942 he moved to Georgia Department of Public Health where he started studies in hookworm and other intestinal helminths common in children from rural areas. Soon after, in 1945 he joined Tulane University as an assistant professor in the Department of Parasitology headed by Dr. Ernest Carroll Faust. In 1956, when Dr. Faust retired, Dr. Beaver took his place as Chairman of the Department of Parasitology. In 1958 he became the Willian Vincent Professor of Tropical Diseases and Hygiene.

In addition, from 1967 to 1976 he was the director of the Tulane International Center for Medical Research and Training Program in Cali, Colombia, under the sponsorship of the US National Institutes of Health and Universidad del Valle.

Due to age, Dr. Beaver retired and was named Emeritus Professor in 1976, but his retirement was in name only for he continue to work in his office and laboratory until a few months before his death. He served Tulane for more than 45 years.

Dr. Beaver' interests and experience in parasitology and tropical medicine were broader than most, if not all his contemporaries. He was noted for his work in amebiasis, biology and control of "soil-transmitted" helmints, quantification of infections with intestinal helminths, visceral and cutaneous larva migrans, filariasis, tropical eosinophilia, ocult helminthiasis and the diagnosis of parasites in tissues. These studies lead to the description of the visceral larva migrans syndrome and the identification of the larvae of Toxocara canis as its primary cause. This contribution as well as the widely known two text books he coauthored, Clinical Parasitology and Animals Agents and Vectors of Human Disease, are paramount of his work. Dr. Beaver had more than 150 publications, but this number does not reflect the many papers published by his students and collegues to which be declined to include his name.

Dr. Beaver was President of the American Society of Parasitologists (1968) and the American Society of Tropical Medicine and Hygiene (1969) and he served as Editor of the journal of the latter society for 20 years. He recieved many honors, including the Walter Read Medal in 1990, and was consultant of several national and international organizations, including WHO expert panels and committees in many countries of Mid and Far East.

On a personal note, my arrival to Tulane in 1956 coincided with that of other four students: Ash, Little, Orihel and Pacheco. We were the first original five who started and finished a PhD under Dr. Beaver' overall direction. All of us became prefessional parasitologists.

In 1961, before I departes for Cali, Colombia, Dr. Beaver emphasizes to me that when in an area full of interesting problems the important decision to make was what not to do, rather than the opposite, to avoid becoming overwelmed by activities which can be dealt with only superficially. And he was so right. I am not sure, however, if I always followed his advice. One memorable experience was the time when he told me that the fact $I$ have been for so many years in charge of the Tulane Center in Cali was not necessarly because I was a good scientist but rather because in most instances I had shown to have common sense. At the time it was not clear to me what Dr. Beaver meant. Now I know that it was a complement and as a by product I frequently state that common sense is the less common of all senses.

Dr. Beaver was much more than a professor or a director but rather a friend, coffidant and advisor of both personal and other sort of problems to the many people who had the fortune to train under him. His advice always was right on target and it was very much appreciated. 